13 Germany

14 d Institute of Molecular and Clinical Ophthalmology Basel, Mittlere Straße 91, 4056 Basel,

15 Switzerland

\section{Altered functional connectivity relates to motor performance deficits in bipolar but not unipolar depression}

\section{Author affiliations:}

a Laboratory of Systems Neuroscience and Imaging in Psychiatry (SNIP-Lab), Department of Psychiatry and Psychotherapy, University Medical Center Göttingen (UMG), Von-SieboldStraße 5, 37075 Göttingen, Germany

b Cognitive Neuroscience Laboratory, German Primate Center, Kellnerweg 4, 37077 Göttingen, Germany

e Leibniz ScienceCampus Primate Cognition, Kellnerweg 4, 37077 Göttingen, Germany

\author{
Renate Schweizer ${ }^{\mathrm{c}, \mathrm{e}}$, Roberto Goya-Maldonado, ${ }^{\mathrm{a}, \mathrm{e}}$
}

Correspondence to:

9 PD Dr. med. Roberto Goya-Maldonado

Universitätsmedizin Göttingen

Klinik für Psychiatrie und Psychotherapie

Labor für systemische Neurowissenschaften und Bildgebung in der Psychiatrie (SNIP-Lab)

Von-Siebold-Str. 5
D-37075 Göttingen

Germany

6 Phone: +49 551-39-22244

27 E-mail: roberto.goya@med.uni-goettingen.de 
medRxiv preprint doi: https://doi.org/10.1101/2021.11.26.21266905; this version posted November 28, 2021. The copyright holder for this

\section{Abstract}

30 Underpinnings of psychomotor deficits in bipolar and unipolar depression remain

31 underexplored. Here, we hypothesize that motor performance deficits in patients may be

32 partially explained by altered functional connectivities between hand primary motor cortex

33 and posterior cingulate cortex with supplementary motor area.

3495 participants between 18-65 years of age, including bipolar depressed, unipolar depressed,

35 and sex-, age-, and education-matched healthy controls, participated in this observational

36 study with two separate visits about five weeks apart, during which the patients received

37 psychopharmacological treatment. Motor performance was measured with a finger-tapping-

38 task and related to functional connectivity from individual seeds in hand primary motor

39 cortex and posterior cingulate cortex as well as to the default mode and sensory motor

40 networks from resting state functional MRI data.

4179 participants (45.6\% females, 21 bipolar depressed, 27 unipolar depressed and 31 healthy

42 controls) were included in the analysis. Using a finger-tapping-task, the groups differed in

43 motor performance (ANOVA factor "group" $F(2,76)=4.122 ; p=0.020$ ) and bipolar

44 depressed but not unipolar depressed showed performance deficits compared to controls

45 (post-hoc-test $p=0.023$ and $p=0.158$ respectively). Behavioral performance correlated with

46 functional coupling of posterior cingulate cortex - supplementary motor area, but not with

47 coupling of primary motor cortex - supplementary motor area at cluster-wise correction level

$48 p F W E c<0.05$. Correlation differences were seen in posterior cingulate cortex -

49 supplementary motor area (healthy controls>bipolar depressed, unipolar depressed >bipolar

50 depressed) at second visit and in primary motor cortex - supplementary motor area (bipolar

51 depressed>unipolar depressed) at both visits at cluster-wise correction level $p F W E c<0.05$.

52 Motor performance did not relate to functional coupling of sensory motor network - anterior

53 (visit $1 p=0.375$, visit $2 p=0.700$ ) or - posterior (visit $1 p=0.903$, visit $2 p=0.772$ )

54 default mode network.

55 Motor performance deficits were seen exclusively in bipolar depressed and related to reduced 56 posterior cingulate cortex - supplementary motor area functional connectivity at rest. Our results shed new light on a possible disruption in the anticorrelation between these regions, which seems fundamental for the preservation of motor skills. Given that nuisance factors were controlled for in the study, it is unlikely that the main results are biased by lefthanders,

60 medication load, seed volumes, or differences in movements during MRI scanning. If these 
61 findings are confirmed, new targeted non-invasive interventions, such as repetitive 62 transcranial magnetic stimulation, may be more effective against psychomotor deficits in 63 bipolar depression, when aimed at modulating the supplementary motor area.

64 Keywords: bipolar disorder; major depressive disorder; finger tapping; posterior cingulate 65 cortex; supplementary motor area

\section{Abbreviations ${ }^{1}$}

\section{1. Introduction}

68 Psychomotor functioning involves processes that range from planning, initiating and 69 executing movements. ${ }^{1, \text { for review see } 2}$ Slower or inefficient information processing may derive 70 from alterations in particular neural regions, or entire networks, that are essential to the 71 circuitry. ${ }^{3-7}$ The precentral gyrus contains the primary motor cortex (M1), which is in charge 72 of starting the execution loop of movements of the contralateral limb. ${ }^{8,9}$ For the coordinated 73 adjustment of muscles implicated in the intended hand movement, the supplementary motor 74 area (SMA) integrates signals of frontal planning with sensorial, proprioceptive and cognitive 75 information from other brain regions and forwards it to the M1. ${ }^{8-10 \text {,for a review see } 11}$ Another 76 pivotal region involved in successful motor responses is the posterior cingulate cortex (PCC), 77 a region belonging to the default mode network (DMN). PCC plays a role in integrating signals from somatosensory areas and dorsal visual stream via parietal cortical areas for spatial processing and action in space. ${ }^{\text {for review see } 12}$ In stroke patients with impairments in motor performance, strengthened resting state functional connectivity between the M1 and the PCC was found to be critical for improvements in motor performance. ${ }^{17}$ Studies have shown that the PCC is also involved in emotional processing and rumination of negative 83 thoughts. ${ }^{13-16}$ This makes it an interesting target for research on depression, since psychomotor symptoms in neuropsychiatric disorders may involve behaviors arising from

\footnotetext{
${ }^{1}$ Abbreviations: AAL = automated anatomical labeling; BD = Bipolar depressed; BDI-II = Beck-DepressionRating-Scale second version; DMN = Default mode network; EPI = Echo planar imaging; FTT = Fingertapping-task; gICA = group independent component analysis; GLM = general linear model; FWHM = full width at half maximum; HAMD = Hamilton depression rating scale; $\mathrm{HC}=$ Healthy controls; ICD-10 = International Statistical Classification of Diseases and Related Health Problems 10th Revision; M1 = Primary motor cortex; MADRS = Montgomery Åsberg Depression Rating Scale; MNI = Montreal Neurological Institute; MPRAGE = magnetization prepared rapid gradient echo; $\mathrm{PCC}=$ Posterior cingulate cortex; $\mathrm{p}$ FWE = family-wise error correction level; $\mathrm{p}$ FWEc = cluster-wise correction level; rmANOVA = repeated measures ANOVA; rs-fMRI = Resting state functional MRI; SCL-90-R = Symptom-Checklist-90-R; SMA = Supplementary motor area; SMN = Sensory motor network; UD = Unipolar depressed; UMG = University Medical Center Göttingen; YMRS = Young-Mania-Rating-Scale
} 
85 more than just the motor circuitry. ${ }^{\text {for }}$ review see 6 To broaden the understanding of the 86 contribution of M1 and PCC also in motor performance deficits in depression, ${ }^{18-21}$ studies

87 that unveil their longitudinal functional connectivity are crucial.

88 Deficits in psychomotor functioning is a typical symptom cluster of major depressive disorder 89 and the depressive phase of bipolar disorder ${ }^{22,23}$ and can make a decisive contribution to 90 unsuccessful treatment ${ }^{24,25}$ as well as to social functioning. ${ }^{26}$ In spite of their impact on 91 patient outcomes, their manifestation is often assumed to be either part to residual symptoms 92 or medication side effects, leaving their neural correlates and development of potentially 93 targeted treatments poorly explored. The identification of more objective differences 94 involving motor performance and its neural correlates in groups of bipolar depressed (BD), 95 unipolar depressed (UD) patients and healthy controls (HC) could support the development of 96 novel biomarkers. Furthermore, such neurofunctional biomarkers of BD and UD can offer the 97 chance to better understand the basis of motor symptom manifestation and treatment 98 improvement, ${ }^{\text {for review see } 27}$ for example, by applying more targeted transcranial magnetic 99 stimulation (TMS) protocols. for review see 28

100 Different paradigms can be used to assess and compare the motor performance of UD, BD, $101 \mathrm{HC}$ and recovered patients. ${ }^{29-34}$ In the present study, we have chosen the finger-tapping-task 102 (FTT) paradigm, considering that it dismisses working memory, ${ }^{35,36}$ which allows clearer 103 conclusions about the movement process itself. It has been previously shown that motor 104 performance in FTT is impaired in $\mathrm{BD},{ }^{18,19}$ but not always in UD, ${ }^{5,20,21,37-39}$. This reinforces 105 an importance of understanding the underlying brain mechanisms leading to such differences. 106 In light of possible residual motor symptoms, ${ }^{40,41}$ the fundamental evaluation of motor 107 performance, e.g. using the FTT, related to baseline M1 and PCC functional connectivity in 108 depressed subjects undergoing treatment remains unexplored to our knowledge. Therefore, 109 our aim with this study was to test whether resting state functional connectivity of M1 and 110 PCC with SMA, which is accessible on the MRI scanner to all patients, regardless of how 111 severely depressed they are, can explain behavioral differences in subjects. Functional 112 connectivity between the right M1 and the SMA, an integrative center of the sensory motor 113 network (SMN), can be a positive predictor of performance during the FTT in HC. ${ }^{42}$ Thus, 114 baseline functional dysconnectivities with the SMA could potentially explain behavioral 115 differences between BD and UD patients in contrast to HC. 
116 Large-scale networks can differ according to mood states in bipolar disorder. ${ }^{43-45} \mathrm{~A}$ model

117 involving the interaction between the SMN and the DMN has been recently suggested to

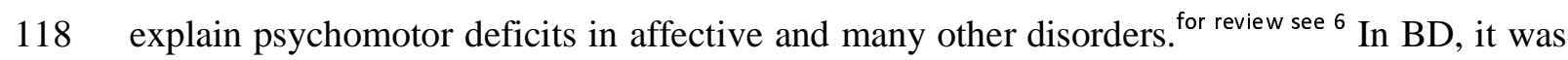

119 proposed that the interaction between networks is imbalanced towards the DMN in 120 depressive states, whereas imbalanced towards the SMN in manic states. ${ }^{43,46}$ While this

121 remains to be tested, evidence of hyperconnectivity between the SMN and the DMN in

122 bipolar patients in a depressed state seems to contradict this idea. ${ }^{44}$ As the balanced coupling

123 between task positive and task negative networks is important for the proper execution of

124 motor tasks in $\mathrm{HC}^{47}$ we explore here whether the relationship between SMN-DMN networks

125 can better explain possible FTT differences between groups.

126 Thus, in the present investigation, we expect that FTT motor performance is impaired in BD 127 and UD in relation to $\mathrm{HC}$, a difference that could decrease after antidepressant treatment. We 128 hypothesize that the functional connectivity of M1 and PCC (our regions of interest for the 129 seed analysis) with the SMA relates to FTT motor performance. Finally, we explore if the 130 cross-correlation between the entire SMN and DMN (rather than the regions of interest) 131 better explains differences in the level of motor performance.

\section{2. Materials and methods}

\section{$134 \quad 2.1$ Protocol}

135 The study was performed at the University Medical Center Göttingen (UMG) after approval 136 of the research protocol by the local Ethics Committee. All participants provided their verbal 137 and written informed consent after a detailed explanation of the research protocol. Patients 138 experiencing a depressive phase of major depressive disorder (UD) or bipolar disorder (BD) 139 (cf. ICD-10) and sex, age and education matched $\mathrm{HC}$ were recruited by announcements at the 140 local University, the UMG Psychiatric Center as well as the local Asklepios Psychiatric 141 Hospital.

142 All participants were between 18 and 65 years old. Exclusion criteria were: current or 143 previous brain injury, current or past neurological disease, current use of illegal drugs, 144 inability to perform the tasks or to undergo MRI sessions. 
medRxiv preprint doi: https://doi.org/10.1101/2021.11.26.21266905; this version posted November 28, 2021. The copyright holder for this

145 We collected individual information about the handedness ${ }^{48}$ and being lefthanded was not an

146 exclusion criterion in order to consider all the handedness variability in the clinical sample.

147 And to consider the influence of this variable, we also complement the analyses with models

148 excluding lefthanders.

149 The study comprised two assessments of two consecutive days separated by approximately 5 150 weeks (Fig. 1). Between evaluations, patients received psychopharmacological treatment for 151 the depressive episode at the psychiatric hospital by their caregiver physicians, who were 152 independent in their treatment choices from the research group that conducted the study 153 (naturalistic design). HC participated in the same study protocol, but received no treatment. 154 All subjects were instructed to abstain from alcohol for at least 24 hours before and to refrain 155 from consuming nicotine or caffeine for at least two hours before the assessments. On each 156 day the participants performed the FTT, on the second day followed by a structured interview 157 led by a trained person and - in case of medication with measurable blood metabolites 158 (Supplementary Table 1) - a blood sample was taken immediately prior to the MRI session to 159 measure their blood medication levels.

160 Severity of symptoms in patients was assessed with the Montgomery Åsberg Depression 161 Rating Scale (MADRS), the Young-Mania-Rating-Scale (YMRS), and the Beck-Depression162 Rating-Scale second version (BDI-II), the first two rated within the structured interview, the 163 latter, self-rated. We used the BDI-II in all our groups as our primary scale to implement the 164 degree of depressive symptomatology in the analyses. The BDI-II is well correlated with 165 other-rated scales (MADRS, Hamilton depression rating scale (HAMD)) and has a focus on 166 cognitive aspects of depression and less on mood and anxiety or neurovegetative aspects, ${ }^{49}$ 167 which is in line with the research focus of this study. Furthermore, the BDI-II as a self-rated 168 scale showed more correlation to brain metabolism in resting state positron emission 169 tomography than HAMD as an other-rated scale, indicating that BDI-II can be more strongly 170 related to basal brain functioning. ${ }^{50}$ To account for the amount of psychotropic medication 171 used per patient, an extended concept previously established as medication load ${ }^{51-55}$ was 172 implemented (Supplementary material, chapter 1.1). In HC, to verify the absence of potential 173 psychiatric symptoms, the self-rated Symptom-Checklist-90-R (SCL-90-R) was used. 
medRxiv preprint doi: https://doi.org/10.1101/2021.11.26.21266905; this version posted November 28, 2021. The copyright holder for this

\section{$174 \quad 2.2$ Finger-Tapping-Task}

175 The FTT was performed on a computer with an adapted keyboard that contained only the

176 keys 1 to 4 . The subjects tapped with the digits of the non-dominant hand not using the 177 thumb. The task consisted of 12 intervals of 30 seconds duration in which the tapping was 178 performed with intervals of 20 seconds without digit movements between them. The entire 179 tapping sequence was presented on the computer monitor with numbers associated with 180 digits: 1 = little finger, $2=$ ring finger, $3=$ middle finger, $4=$ index finger. On the two days 181 of the first visit the sequence "4-1-3-2-4" was used, on the two days of the second visit the 182 sequence "1-4-2-3-1" was used (Fig. 1). The participants were instructed to press the keys as 183 fast and accurately as possible. No feedback was given on the performance of the task. The 184 mean from the number of correctly tapped sequences of the last three of the 12 tapping 185 intervals of the first days of the visits where used as a score to quantify the motor 186 performance - as they are expected to represent the performance plateau. ${ }^{36,56}$ The number of correctly typed sequences accounts for speed and accuracy. 35,36

\section{$188 \quad 2.3$ Functional connectivity}

189 The functional and structural images were acquired with a 3T Siemens Magnetom Tim Trio, on Syngo VB-17a (Erlangen, Germany) and a 32-channel head coil. Structural whole-brain T1-weighted images were realized with a magnetization prepared rapid gradient echo (MPRAGE) sequence (repetition time: $2250 \mathrm{~ms}$, echo time: $3.26 \mathrm{~ms}$, inversion time: $900 \mathrm{~ms}$,

193 flip angle: $9^{\circ}$, field or view: $256 \mathrm{~mm}$, spatial resolution: $1 \mathrm{~mm}$ x $1 \mathrm{~mm}, 176$ slices, acquisition 194 time: 8:26 min) and a resulting voxel size of $1 \mathrm{~mm} \times 1 \mathrm{~mm} \times 1 \mathrm{~mm}$.

195 Resting state functional MRI (rs-fMRI) was measured with an gradient echo EPI (echo planar imaging) sequence (repetition time: $2500 \mathrm{~ms}$, echo time: $33 \mathrm{~ms}$, flip angle $70^{\circ}$, multi-bandfactor 3, field of view $210 \mathrm{~mm}$, spatial resolution: $2 \mathrm{~mm} \times 2 \mathrm{~mm}, 60$ slides with $2 \mathrm{~mm}$ thickness, distance factor 10\%, 125 volumes (first 5 volumes deleted)) with a total acquisition time of 5:25 min, voxel size of $2 \mathrm{~mm} \times 2 \mathrm{~mm} \times 2 \mathrm{~mm}$ and a slice orientation along the anterior-posterior commissure.

201 Brain images were analyzed with SPM12 (www.fil.ion.ucl.ac.uk/spm, Wellcome Trust 202 Centre for Neuroimaging, London, United Kingdom) based on MATLAB 2015b 203 (MathWorks, Natick, Massachusetts) The following preprocessing steps were performed: 204 default temporal high-pass filtering SPM12 at $<0.008 \mathrm{~Hz}$, slice-time-correction, realignment 
medRxiv preprint doi: https://doi.org/10.1101/2021.11.26.21266905; this version posted November 28, 2021. The copyright holder for this

205 with unwarping SPM12; spatial normalization with the deformation field from FreeSurfer 206 Version 6.0 (https://surfer.nmr.mgh.harvard.edu/) run on an Ubuntu 18.0 to the standard 207 Montreal Neurological Institute (MNI) 152 brain at $2 \mathrm{~mm}$ spatial resolution; spatial 208 smoothing with a Gaussian kernel of $6 \mathrm{~mm}$ full width at half maximum (FWHM); nuisance209 regression of white matter and cerebral spinal fluid as well as motion correction with an 210 automatized independent component analysis based cleaning procedure (ICA-AROMA v0.3211 bet, available from: https://github.com/maartenmennes/ICA-AROMA). ${ }^{57}$ To ensure all 212 autocorrelative signal was regressed out, a visual inspection of all data for quality control was 213 performed. If potential noise artefacts remained, they were added as additional "noise" 214 components to the automatically identified by ICA-AROMA and the cleaning procedure was 215 rerun. In addition to this extensive correction of movement we also assessed potential bias 216 due to different extend of movement between the groups by comparing individual root mean 217 squares based on frame-by-frame displacement of adjacent volumes in $\mathrm{mm}$ between the 218 groups in an repeated measures ANOVA (rmANOVA). ${ }^{58}$

219 Seed-based analyses aimed to address functional connectivity differences and its influences 220 on motor performance of the right hemisphere hand M1 and the PCC, especially to the SMA 221 as the core region of our hypotheses. To define the M1 gray matter seeds, we combined the 222 anatomical T1 information from the precentral gyrus from FreeSurfer segmentation with a $2237 \mathrm{~mm}$ radius spherical seed, defined using the SPM toolbox MarsBaR version 0.44 224 (http://marsbar.sourceforge.net/), which was centered at the MNI-coordinates 40 -20 54 (x, y, 225 z) for the right hemisphere hand M1 from a meta-analysis of functional MRI data of hand 226 movement tasks. ${ }^{59}$ The overlap between these two sources was carefully inspected for 227 consistency in every individual subject's data (see an example for precise coverage of the 228 grey matter with a seed based on this technique in Fig. 1). To make sure that differences in 229 functional connectivity did not stem from differences in the seed volume, we checked if the 230 volume of the individualized masks differed between groups or time with an rmANOVA in 231 SPSS (for results see Supplementary material, chapter 2.2). The newly established seed 232 definition technique was also applied to create seeds for the PCC (MNI coordinates 0 -53 26 $233(\mathrm{x}, \mathrm{y}, \mathrm{z})$ ) (for an example see Fig. 1), centered in the position used for the investigation of 234 motor impairments in stroke. ${ }^{17}$ 
medRxiv preprint doi: https://doi.org/10.1101/2021.11.26.21266905; this version posted November 28, 2021. The copyright holder for this preprint (which was not certified by peer review) is the author/funder, who has granted medRxiv a license to display the preprint in perpetuity.

All rights reserved. No reuse allowed without permission.

$\underline{A}$

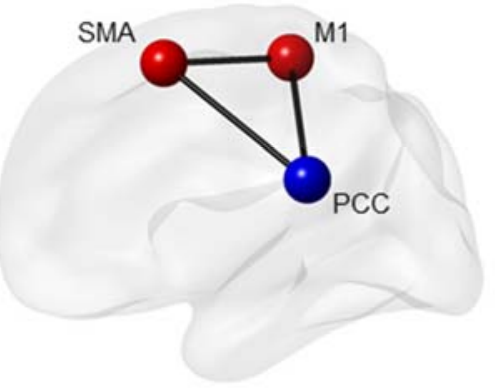

$\underline{B}$

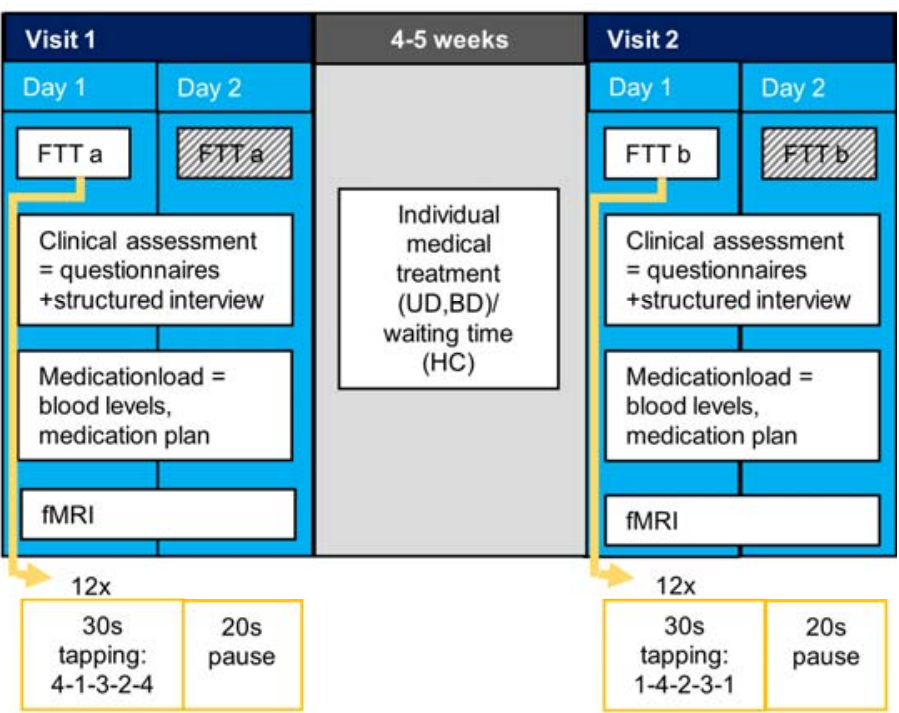

$\underline{\mathbf{D}}$ $\underline{\mathbf{c}}$

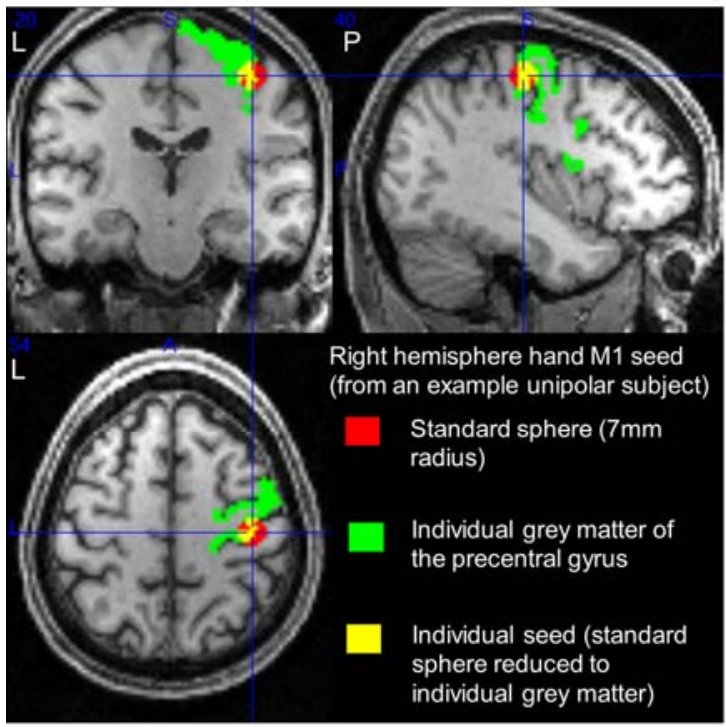

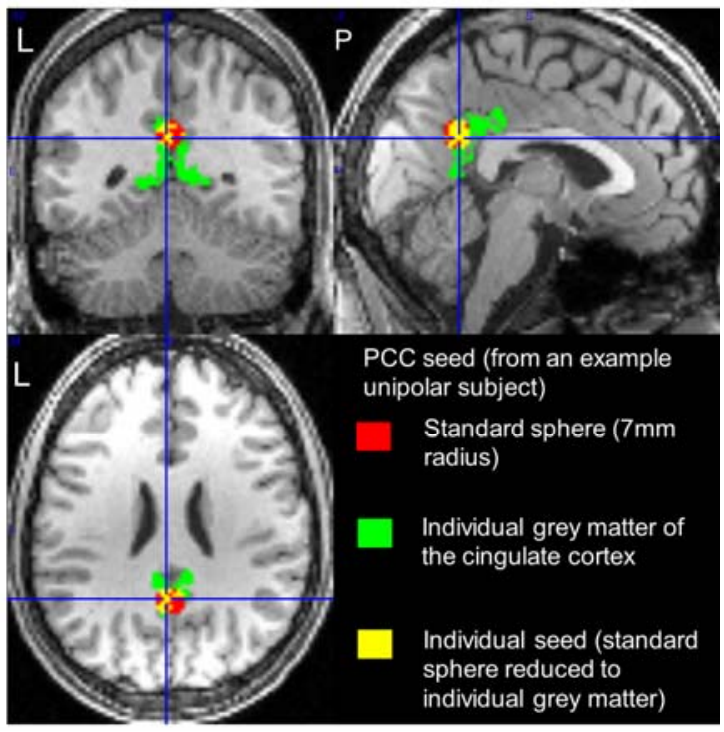

236 Figure 1 Methods (A) Connectivity model between regions of interest: supplementary motor area (SMA) and right hemisphere hand primary motor cortex (M1) as part of the sensory motor network (red), posterior cingulate 238 cortex (PCC) as part of the default mode network (blue); (B) Study design: unipolar (UD), bipolar (BD) 239 depressed and healthy control subjects (HC) performed the finger-tapping-task (FTT) on both days of both 240 visits, FTTa and FTT b versions as described in methods section. The data of the second days was not used for 241 the analysis of motor performance. The clinical assessment and the MRI sessions took place on one of the days.

242 The blood sample was taken as close as possible before the MRI measurement; (C) Seed definition technique: 243 exemplification of the overlapping area (yellow) based on FreeSurfer individual segmentation of grey matter 244 (green) and a spherical seed (red) at the MNI coordinates $\mathrm{x}=40, \mathrm{y}=-20, \mathrm{z}=54$ of functional coordinates for 245 right hemisphere hand motor cortex $(\mathrm{M} 1)^{59}(\mathrm{D})$ and at $\mathrm{x}=0 \mathrm{y}=-53, \mathrm{z}=2$ for the posterior cingulate cortex ${ }^{17}$.

246 The time courses of these seeds were bandpass filtered $(0.01 \mathrm{~Hz}-0.1 \mathrm{~Hz})$ before being 247 included into a general linear model (GLM) in SPM12 for the first level analysis. According 
medRxiv preprint doi: https://doi.org/10.1101/2021.11.26.21266905; this version posted November 28, 2021. The copyright holder for this

248 to the known task-positive and task-negative activations in the right hemisphere hand M1 and

249 PCC respectively, we focused on brain regions positively correlated when seeding in the right

250 hemisphere hand M1 and regions negatively correlated (anticorrelated) when seeding in the 251 PCC.

252 To investigate potential full network interconnection deficiency between SMN and DMN in 253 depressive patients, a group independent component analysis (gICA) was performed using 254 MELODIC Version 3.14 in FSL (FMRIB's Software Library, www.fmrib.ox.ac.uk/fsl), ${ }^{60}$ to 255 be able to estimate correlation between the time courses of these networks in all groups 256 before and after intervention. The gICAs were performed for each group and each visit 257 separately. Then, all the components were inspected selecting the components reflecting $258 \mathrm{SMN}$, anterior DMN and posterior DMN. The time course of the network signal from every 259 subject was extracted separately for each selected component. For every subject a correlation 260 coefficient for the correlation between the time courses of the SMN and the anterior DMN as 261 well as for the correlation between the SMN and the posterior DMN was calculated using 262 MATLAB 2015b (MathWorks, Natick, Massachusetts).

\section{$263 \quad 2.4$ Statistical Analysis}

264 The FTT was analyzed with an rmANOVA for motor performance in IBM SPSS Statistics 265 Version 26. In the main analysis no covariates were included, but to check for influencing 266 effects, the analysis was repeated with the covariates sex, age, education, change of the 267 medication load and change in BDI-II, which have the potential to influence the motor 268 performance. ${ }^{25,61-65}$ Furthermore, models with only the patient groups were created to 269 consider potential effects of years since first episode, age of onset, number of depressive 270 episodes, change in MADRS and change in YMRS, which have been described in the 271 literature. $^{29,63}$ The statistical threshold for the tests was set to two-tailed $p<0.05$. If the 272 assumption of homogeneity of variance was met for the ANOVAs, we used the Bonferroni 273 post-hoc-test to correct for multiple testing. But if this assumptions was not met, we used the 274 Games-Howell post-hoc-test.

275 For the seed based rs-fMRI data, two SPM full factorial models with group and time as 276 factors were built for the two seeds in the second level analysis, one without covariates and 277 one with medication load as covariate-of-no-interest to control for potential differences 278 stemming from the load of medication the patients received. In addition, linear regressions 
279 with functional connectivity of the seed and motor performance were calculated for the whole 280 study population.

281 The correlation coefficients were used for an rmANOVA model calculated in SPSS to 282 investigate whether possible correlations between the networks differed between groups or 283 time. Additionally, a linear regression was performed for each visit to test for a relationship 284 between the SMN-DMN time course correlations and the motor performance.

285 In regions belonging to our a priori hypothesis, we considered the statistical threshold at the 286 cluster-wise correction level $(p F W E c<0.05)$ to reduce the probability of both false-positive 287 and false-negative results. Otherwise, we considered the family-wise error correction level $(p$ $288 F W E<0.05)$ to reduce the probability of false-positive results. The labeling of functional 289 imaging clusters was performed according to the automated anatomical labeling (AAL) 290 atlas. $^{66}$

\subsection{Data availability}

292 The data supporting the findings of this study are available from the corresponding author 293 upon request. Due to restrictions in the data sharing consent obtained from the study 294 participants the data are not publicly available.

295 3. Results

296 From 95 participants, 11 were unable or unwilling to complete the entire study, one 297 participant performed the FTT with the wrong hand and four participants were excluded due 298 to abnormalities in the anatomical scans, e.g. intracranial epidermoid cysts. Therefore, data 299 from 79 participants (31 HC, 27 UD, 21 BD - 18 Type I, three Type II) were taken into final 300 analysis. One participant from each of the $\mathrm{HC}$ and $\mathrm{BD}$ groups and two participants of the UD 301 group were lefthanded.

\section{$302 \quad 3.1$ Characterization of groups}

303 The mean time between the two visits was 4.9 weeks (SD 0.8). A complete evaluation of the 304 characteristics between groups is presented in Table 1. In line with our matching, the groups 305 were comparable in terms of sex, age and years of education. The patient groups did not 
306 differ in terms of the history of their disease measured by age of onset, years since first 307 episode and number of depressive episodes. The healthy controls did not exceed the threshold 308 of normality in the global severity index of the SCL-90-R score.

309 The severity of the depressive episode was evaluated during the study and at both visits the 310 patient groups showed comparable depressive episode severity according to the BDI-II 311 scores. The comparison of the difference in BDI-II scores of visit 1 and 2 between groups 312 revealed a significantly higher difference only for UD compared to HC (Table 1). An 313 rmANOVA with the BDI-II scores revealed a significant change between visit 1 and 2 that 314 seems driven by a stronger reduction in the patient groups (factor "time $F(1,76)=15.660, p$ $315<0.001$; interaction "group x time" $F(2,76)=6.035, p=0.004$; factor "group" $F(2,76)=$ $31641.138, p<0.001)$.

317 In MADRS, the severity of depressive symptoms was significantly higher in UD, but only at 318 the first visit (Table 1). An rmANOVA with the MADRS scores revealed a significant 319 reduction between visit 1 and 2 for both patient groups but stronger in UD than in BD (factor 320 "time" $F(1,46)=21.067, p<0.001$; interaction "group x time" $F(1,46)=5.179, p=0.028$; 321 factor "group" $F(1,46)=8.903, p=0.005)$. There was a significant difference seen for 322 YMRS scores with BD showing higher scores and a stronger reduction across time than UD 323 in an rmANOVA (factor "time $F(1,46)=10.067, p=0.003$; interaction "group x time" $324 F(1,46)=7.024, p=0.011$; factor "group" $F(1,46)=7.491, p=0.009)$.

325 Although only bipolar patients in the current depressive episode were recruited, the 326 symptoms were mixed in some patients. At the first visit, three bipolar patients showed 327 subclinical depressive symptoms (BDI-II score $\leq 8$ and MADRS score $\leq 12)$, five showed 328 manic symptoms (YMRS score > 9) and one showed both manic (YMRS score of this subject 329 at visit $1=14$ ) and depressive (BDI-II score of this subject at visit $1=53$; MADRS score of 330 this subject at visit $1=28)$ symptoms. Even though being subclinical $\left(M_{Y M R S} \leq 9\right)$, the BD 331 group showed a significantly higher YMRS score on visit 1 compared to the UD, as well as a 332 greater change in YMRS score between the two visits. To confirm that the main results were 333 not driven by the individuals with manic symptoms characteristics or subclinical depressive 334 symptoms characteristics, we compared mean motor performance scores of the original BD 335 group, with a subgroup of BD with clinical depressive symptoms only, which showed 336 comparable values (BD visit $1=8.6 \pm 4.6(M \pm S D)$ (Fig. 2); BD visit 1 with clinical 337 depressive symptoms only: $8.4 \pm 4.9(M \pm S D))$. We also repeated the imaging analysis of 
338 linear regression of motor performance scores and functional connectivity of PCC seeds

339 without the BD subjects showing manic, mixed or subclinical symptoms and the main results

340 could still be identified.

341 No difference in medication load between patient groups was seen at visit 1 or visit 2, but the 342 load in both visits was significantly higher compared to HC, since they were not medicated. 343 Furthermore, the change in medication load between visit 1 and 2 was small in the patient 344 groups (Table 1) and not distinguishable from the $\mathrm{HC}$ on an additional rmANOVA (factor 345 "time" $F(1,76)=2.431, p=0.123$; interaction "group x time" $F(2,76)=1.155, p=0.320$; 346 factor "group" $F(2,76)=48.226, p<0.001)$. For a detailed description of medication taken 347 by the patient groups see tables of chapter 2.1 in the Supplementary material.

348 Table 1: Characteristics of the bipolar (BD), unipolar (UD) and healthy control (HC) groups

\begin{tabular}{|c|c|c|c|c|c|}
\hline & Controls & Unipolar & Bipolar & $\begin{array}{l}\text { Comparison } \\
\text { p-value }\end{array}$ & Meaning of $p$ \\
\hline $\mathbf{N}(\%$ female $)$ & $31(58.1 \%)$ & $27(40.7 \%)$ & $21(33.3 \%)$ & $0.176^{\mathrm{a}}$ & $\begin{array}{l}\text { No difference between } \\
\text { groups }\end{array}$ \\
\hline Age in years & $41.7 \pm 14.3$ & $39.6 \pm 15.3$ & $43.5 \pm 9.8$ & $0.591^{\mathrm{b}}$ & $\begin{array}{l}\text { No difference between } \\
\text { groups }\end{array}$ \\
\hline $\begin{array}{l}\text { Education in } \\
\text { years }\end{array}$ & $16.5 \pm 3.8$ & $15.5 \pm 3.1$ & $16.8 \pm 4.0$ & $0.453^{\mathrm{c}}$ & $\begin{array}{l}\text { No difference between } \\
\text { groups }\end{array}$ \\
\hline $\begin{array}{l}\text { Number } \\
\text { lefthanders }\end{array}$ & $1(3.2 \%)$ & $2(7.4 \%)$ & $1(4.8 \%)$ & $X^{d}$ & $\mathrm{X}^{\mathrm{d}}$ \\
\hline $\begin{array}{l}\text { Age of first } \\
\text { episode }\end{array}$ & $\mathrm{X}$ & $29.5 \pm 15.2$ & $24.7 \pm 9.5$ & $0.182^{\mathrm{b}}$ & $\begin{array}{l}\text { No difference between } \\
\text { groups }\end{array}$ \\
\hline $\begin{array}{l}\text { Years since first } \\
\text { episode }\end{array}$ & $\mathrm{X}$ & $10.1 \pm 9.4$ & $18.9 \pm 13.5$ & $0.161^{\mathrm{b}}$ & $\begin{array}{l}\text { No difference between } \\
\text { groups }\end{array}$ \\
\hline $\begin{array}{l}\text { Number of } \\
\text { depressive } \\
\text { episodes }\end{array}$ & $\mathrm{X}$ & $4.8 \pm 3.8$ & $7.2 \pm 6.1$ & $0.095^{\mathrm{c}}$ & $\begin{array}{l}\text { No difference between } \\
\text { groups }\end{array}$ \\
\hline $\begin{array}{l}\text { Number of manic } \\
\text { episodes }\end{array}$ & $\mathrm{X}$ & $\mathrm{X}$ & $2.9 \pm 3.6$ & $\mathrm{X}$ & $\mathrm{X}$ \\
\hline $\begin{array}{l}\text { Number of } \\
\text { hypomanic } \\
\text { episodes }\end{array}$ & $\mathrm{X}$ & $\mathrm{X}$ & $3.3 \pm 5.0$ & $\mathrm{X}$ & $\mathrm{X}$ \\
\hline BDI-II visit 1 & $2.6 \pm 3.7$ & $29.5 \pm 11.1$ & $21.1 \pm 16.7$ & $<0.001^{\mathrm{b}}$ & $\begin{array}{l}\text { Games-Howell-Post-Hoc- } \\
\text { Test: Difference HC and } \\
\text { UD: } \mathbf{p}<\mathbf{0 . 0 0 1} \text {, HC and } \\
\text { BD: } \mathbf{p}<\mathbf{0 . 0 0 1} \text {, UD and } \\
\text { BD: } \mathbf{p}=0.128\end{array}$ \\
\hline BDI-II visit 2 & $2.3 \pm 4.2$ & $20.2 \pm 14.0$ & $17.1 \pm 13.1$ & $<0.001^{\mathrm{b}}$ & $\begin{array}{l}\text { Games-Howell-Post-Hoc- } \\
\text { Test: Difference HC and } \\
\text { UD: } \mathbf{p}<\mathbf{0 . 0 0 1} \text {, HC and } \\
\text { BD: } \mathbf{p}<\mathbf{0 . 0 0 1} \text {, UD and } \\
\text { BD: } p=0.714\end{array}$ \\
\hline $\begin{array}{l}\text { Delta BDI-II visit } \\
2 \text { - visit } 1\end{array}$ & $-0.2 \pm 2.6$ & $-9.3 \pm 11.9$ & $-3.9 \pm 13.3$ & $0.009^{b}$ & $\begin{array}{l}\text { Games-Howell-Post-Hoc- } \\
\text { Test: Difference HC and } \\
\text { UD: } \mathbf{p}=\mathbf{0 . 0 0 2}, \mathrm{HC} \text { and } \\
\text { BD: } \mathbf{p}=0.437 \text {, UD and } \\
\text { BD: } p=0.327\end{array}$ \\
\hline MADRS visit 1 & $\mathrm{X}$ & $24.2 \pm 8.6$ & $13.9 \pm 10.6$ & $0.001^{c}$ & $\begin{array}{l}\text { Severity of depressive } \\
\text { symptoms is higher in UD }\end{array}$ \\
\hline MADRS visit 2 & $\mathrm{X}$ & $14.3 \pm 10.2$ & $10.5 \pm 8.3$ & $0.179^{c}$ & $\begin{array}{l}\text { No difference between } \\
\text { groups }\end{array}$ \\
\hline $\begin{array}{l}\text { Delta MADRS } \\
\text { visit } 2 \text { - visit } 1\end{array}$ & $\mathrm{X}$ & $-9.9 \pm 10.3$ & $-3.3 \pm 9.3$ & $0.028^{c}$ & $\begin{array}{l}\text { Reduction in the severity } \\
\text { of depressive symptoms is } \\
\text { higher in UD }\end{array}$ \\
\hline YMRS visit 1 & $\mathrm{X}$ & $1.7 \pm 2.6$ & $6.1 \pm 6.9$ & $0.012^{b}$ & $\begin{array}{l}\text { Severity of manic } \\
\text { symptoms (mixed } \\
\text { episode) is higher in BD }\end{array}$ \\
\hline YMRS visit 2 & $\mathrm{X}$ & $1.4 \pm 1.7$ & $2.3 \pm 3.5$ & $0.222^{\mathrm{b}}$ & $\begin{array}{l}\text { No difference between } \\
\text { groups }\end{array}$ \\
\hline
\end{tabular}


medRxiv preprint doi: https://doi.org/10.1101/2021.11.26.21266905; this version posted November 28, 2021. The copyright holder for this preprint (which was not certified by peer review) is the author/funder, who has granted medRxiv a license to display the preprint in perpetuity.

All rights reserved. No reuse allowed without permission.

$349{ }^{a}$ Chi-Square-Test-Pearson

\begin{tabular}{|c|c|c|c|c|c|}
\hline $\begin{array}{l}\text { Delta YMRS visit } \\
2 \text { - visit } 1\end{array}$ & $X$ & $-0.3 \pm 2.1$ & $-3.7 \pm 6.2$ & $0.025^{\mathrm{b}}$ & $\begin{array}{l}\text { Reduction in the severity } \\
\text { of manic symptoms } \\
\text { (mixed episode) is higher } \\
\text { in BD }\end{array}$ \\
\hline $\begin{array}{l}\text { Medication load } \\
\text { visit } 1\end{array}$ & $0 \pm 0$ & $4.3 \pm 3$ & $4.5 \pm 2.4$ & $\begin{array}{l}\text { No p-value } \\
\text { because of a } \\
\text { variance of } 0 \\
\text { in controls }\end{array}$ & $\begin{array}{l}\text { Games-Howell-Post-Hoc- } \\
\text { Test: Difference HC and } \\
\text { UD: } \mathbf{p}<\mathbf{0 . 0 0 1}, \mathrm{HC} \text { and } \\
\text { BD: } \mathbf{p}<\mathbf{0 . 0 0 1} \text {, UD and } \\
\text { BD: } \mathrm{p}=0.938\end{array}$ \\
\hline $\begin{array}{l}\text { Medication load } \\
\text { visit } 2\end{array}$ & $0 \pm 0$ & $4.1 \pm 2.6$ & $3.8 \pm 2.3$ & $\begin{array}{l}\text { No p-value } \\
\text { because of a } \\
\text { variance of } 0 \\
\text { in controls }\end{array}$ & $\begin{array}{l}\text { Games-Howell-Post-Hoc- } \\
\text { Test: Difference HC and } \\
\text { UD: } \mathbf{p}<\mathbf{0 . 0 0 1} \text {, HC and } \\
\text { BD: } \mathbf{p}<\mathbf{0 . 0 0 1} \text {, UD and } \\
\text { BD: } p=0.925\end{array}$ \\
\hline $\begin{array}{l}\text { Delta medication } \\
\text { load visit } 2 \text { - visit } \\
1\end{array}$ & $0 \pm 0$ & $-0.2 \pm 1.9$ & $-0.7 \pm 2.5$ & $\begin{array}{l}\text { No p-value } \\
\text { because of a } \\
\text { variance of } 0 \\
\text { in controls }\end{array}$ & $\begin{array}{l}\text { Games-Howell-Post-Hoc- } \\
\text { Test: Difference HC and } \\
\text { UD: } p=0.867, \mathrm{HC} \text { and } \\
\text { BD: } p=0.405 \text {, UD and } \\
\text { BD: } p=0.700\end{array}$ \\
\hline
\end{tabular}

$350{ }^{b}$ One-way-ANOVA with Brown-Forsythe correction for inhomogeneity of variance

$351{ }^{c}$ One-way-ANOVA with homogeneity of variance

$352 \quad{ }^{d}$ Analysis repeated without lefthanders

353 Abbreviations: $B D=$ Bipolar depressed; BDI-II = Beck-Depression-Rating-Scale second version; HC =

354 Healthy controls; MADRS = Montgomery Åsberg Depression Rating Scale; UD = Unipolar depressed ; YMRS

355 = Young-Mania-Rating-Scale

\section{$356 \quad 3.2$ Behavioral results}

357 The motor performance differed between groups (ANOVA factor "group" $F(2,76)=4.122$;

$358 p=0.020$; Fig. 2) with BD showing a significantly reduced number of correctly performed

359 finger tapping trials compared to the HC (Post-hoc-test $p=0.023$ ). The UD group showed no

360 performance impairment compared to HC (Post-hoc-test $p=0.158$ ). The BD and UD showed

361 no significant difference (Post-hoc-test $p=1$ ).

362 All groups showed an improvement of their motor performance in visit 2 (ANOVA factor

363 "time" $F(1,76)=33.800 ; p<0.001)$. The improvement did not differ between the groups

364 (interaction "group x time" $F(2,76)=0.230 ; p=0.795$ ). 


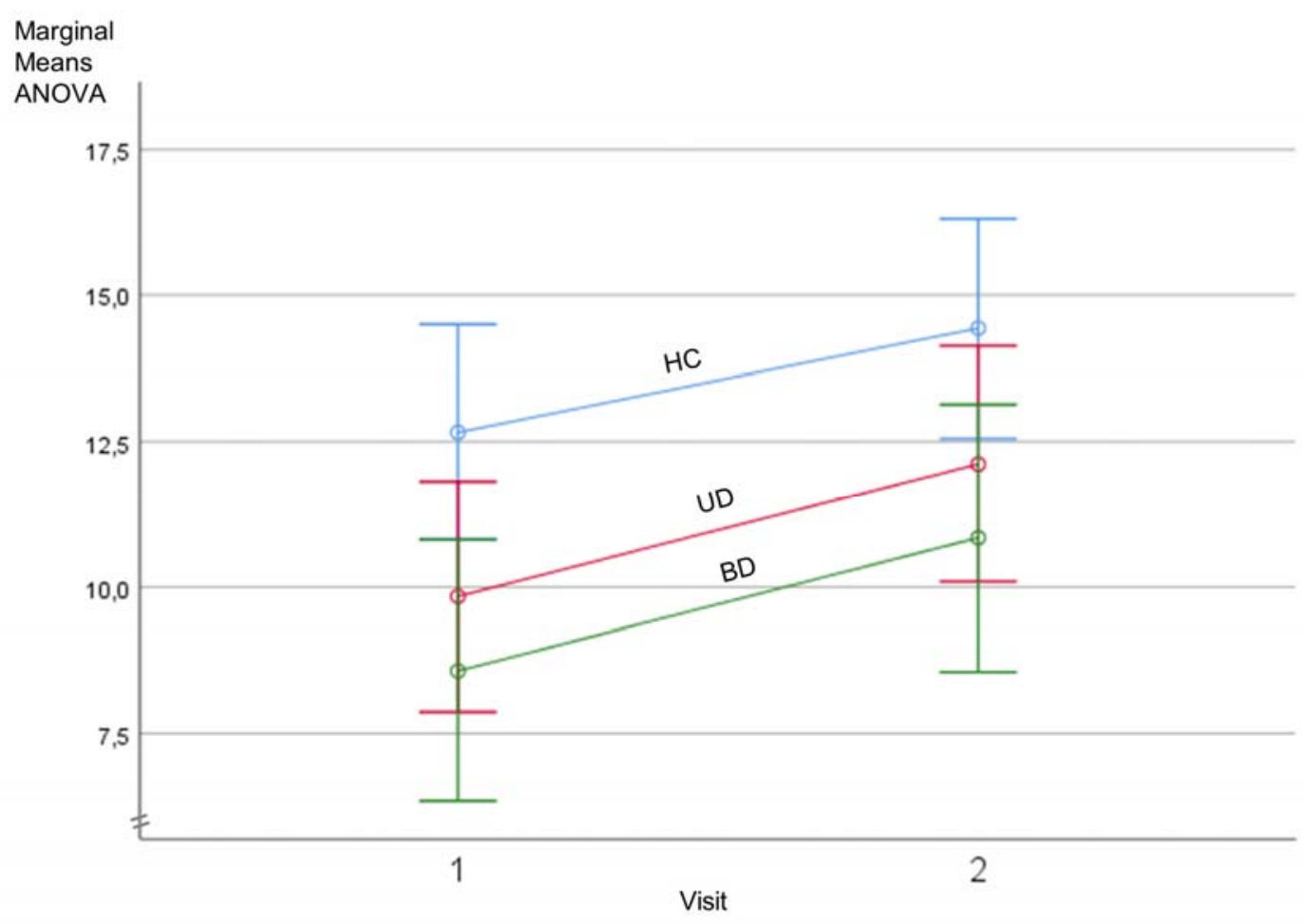

Error bars -> 95\% confidence interval

366 Figure 2 Motor performance scores Marginal means (mean number of correctly tapped sequences per 30 seconds) and confidence intervals from repeated-measures ANOVA of motor performance scores for healthy controls (HC, blue), unipolar (UD, pink) and bipolar (BD, green) patients. The values displayed in the graph are $\mathrm{HC}$ visit $1 M \pm S D=12.7 \pm 6.1$, UD visit $1 M \pm S D=9.8 \pm 4.2$, $\mathrm{BD}$ visit $1 M \pm S D=8.6 \pm 4.6, \mathrm{HC}$ visit $2 M \pm$ $S D=14.4 \pm 5.8$, UD visit $2 M \pm S D=12.1 \pm 5.0$, BD visit $2 M \pm S D=10.8 \pm 4.7$. Significant differences are seen only between $\mathrm{HC}$ and BD (ANOVA factor "group" $F(2,76)=4.122 ; p=0.020$ ) with BD showing a significantly reduced number of correctly performed finger tapping trials compared to the HC (Post-hoc-test $p=0.023)$.

374 By including the covariates sex, age, education, change of medication load and change in 375 BDI-II into the model, the difference in performance between the groups remains significantly different (factor "group" $F(2,71)=5.194 ; p=0.008$ ) as does the comparable performance improvement of the groups across the two visits (interaction "group x time" $F(2,71)=0.067 ; p=0.935)$. However, the general effect of the performance improvement seen across the groups in visit 2 was not present anymore (factor "time" $F(1,71)=0.002$; $p=0.966)$.

381 Influences of covariates on the motor performance in general revealed a negative correlation 382 with age $(F(1,71)=23.542 ; p<0.001)$ and a positive correlation with education 
medRxiv preprint doi: https://doi.org/10.1101/2021.11.26.21266905; this version posted November 28, 2021. The copyright holder for this

$383(F(1,71)=16.183 ; p<0.001)$ for all groups. When limiting the ANOVA to the patient

384 groups, an improvement across visits was present (factor "time" $F(1,46)=23.042$;

$385 p<0.001$ ), which did not differ between the groups (factor "group"; $F(1,46)=1.010 ; p=$

3860.320 ) nor showed an interaction with visits (interaction "group" x "time" , $F(1,46)<0.001$;

$387 p=0.999$ ). These results were maintained, when including the covariates years since first

388 episode, age of onset, number of depressive episodes, change in MADRS and change in

389 YMRS. An older age of first episode $(F(1,41)=5.808 ; p=0.021)$ and more years since first

390 episode $(F(1,41)=4.396 ; p=0.042)$ reduced the motor performance. An increase in YMRS

391 score was positively correlated with a change in motor performance (interaction time $\mathrm{x}$

392 deltaYMRS $F(1,41)=4.525 ; p=0.039)$, a change in MADRS was not (interaction "time $\mathrm{x}$

393 deltaMADRS" $F(1,41)=0.799 ; p=0.377)$. The number of depressive episodes showed a

394 negative correlation with change in performance (interaction "time x number of depressive

395 episodes" $F(1,41)=8.489 ; p=0.006)$.

396 All results hold, when excluding the lefthanders from the analysis.

$397 \quad 3.3$ Functional connectivity

\section{$398 \quad$ 3.3.1 PCC seed functional connectivity}

399 For each group, the seed based functional connectivity between the PCC and the SMA was

400 visible as a negative correlation at $p F W E<0.05$ level, except for the BD group at visit 2.

401 This is in contrast to the seed based connectivity between PCC and M1, were no negative 402 correlation was identified at $p F W E<0.05$ level in all groups and visits. Positive correlation 403 to the PCC was evidenced for regions of the DMN, namely angular gyri, precuneus, cingulate 404 gyri, and middle prefrontal regions (data not shown).

405 The connectivity between PCC and SMA was lower at visit 2 for BD in contrast to HC, as 406 well as to UD, at $p F W E c<0.05$ level (Fig. 3). This remains the same, when excluding the 407 lefthanders from the model. No group differences in the functional PCC-SMA connectivity 408 were observed at visit 1. In addition, no differences in connectivity of PCC to M1 were 409 observed between groups or time. Lastly, all findings from the PCC seed analysis are 410 sustained, when medication load is included in the full factorial models as a regressor-of-no411 interest. 

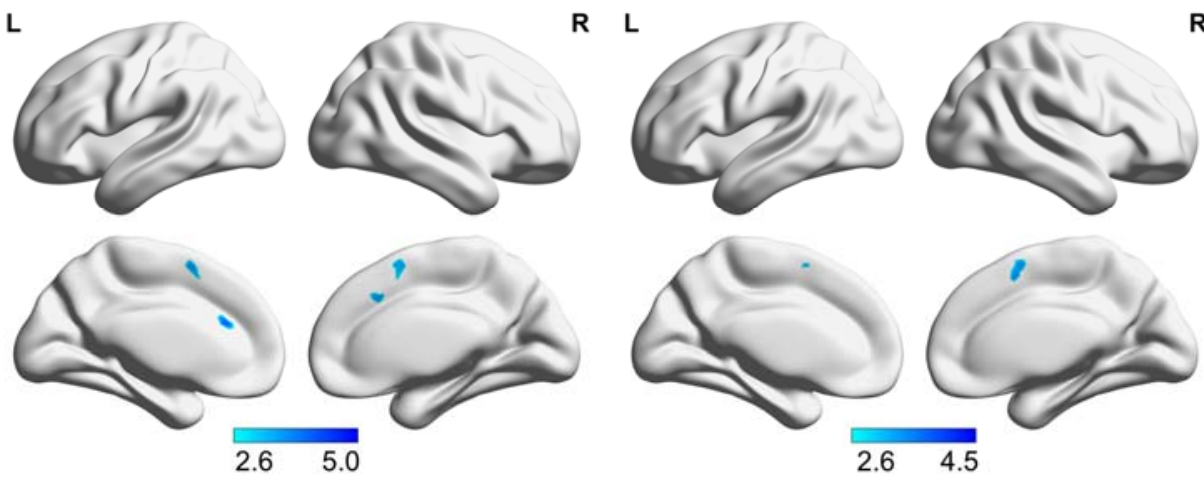

413 Figure 3 PCC connectivity differences Resting state functional connectivity differences of the posterior 414 cingulate cortex (PCC) at the second visit between the bipolar depressive subjects (BD2) and the unipolar 415 depressive (UD2) resp. control (HC2) subjects (p FWEc < 0.05). HC2 showed higher connectivity measured by 416 anticorrelation between the PCC and the bilateral SMA than BD2. UD2 showed higher connectivity measured 417 by anticorrelation between the PCC and the bilateral SMA than BD2. Colorbar represents t-values.

418 The linear regression of the PCC-SMA functional connectivity and the motor performance 419 scores revealed a positive correlation, i.e. the higher the performance the stronger the 420 negative functional connectivity between PCC-SMA (Fig.4). When excluding the lefthanders 421 from analysis the cluster in the SMA maintained at a level of $p<0.001$ uncorrected, but did 422 not survive $F W E c<0.05$ level anymore, most likely due to the reduced power by the lower 423 number of subjects in the analysis.
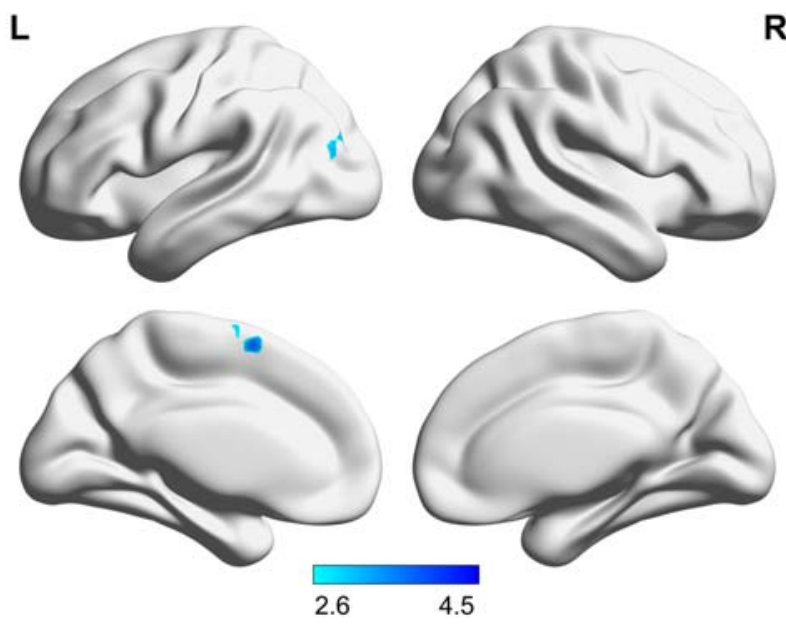

425 Figure 4 PCC connectivity correlated with motor performance Resting state functional connectivity of the 426 posterior cingulate cortex (PCC) linearly correlated with the motor performance in the finger-tapping-task (p 427 FWEc < 0.05). The motor performance is correlated with the connectivity (anticorrelation) strength between the 428 PCC and the left supplementary motor area (SMA). Colorbar represents t-values. 
medRxiv preprint doi: https://doi.org/10.1101/2021.11.26.21266905; this version posted November 28, 2021. The copyright holder for this preprint (which was not certified by peer review) is the author/funder, who has granted medRxiv a license to display the preprint in perpetuity.

All rights reserved. No reuse allowed without permission.

429 On the other hand, the linear regression of the PCC-M1 functional connectivity and the motor

430 performance scores showed no linear relationship. Above all, supporting the idea that lower

431 PCC-SMA anticorrelation in BD is related to their behavioral impairment, a partial overlap in

432 SMA is seen between the functional connectivity differences with other groups and the linear

433 regression with motor performance (Fig. 5). In other words, part of the SMA in BD relates to

434 both reduced performance in FTT and reduced functional connectivity to PCC, not M1.

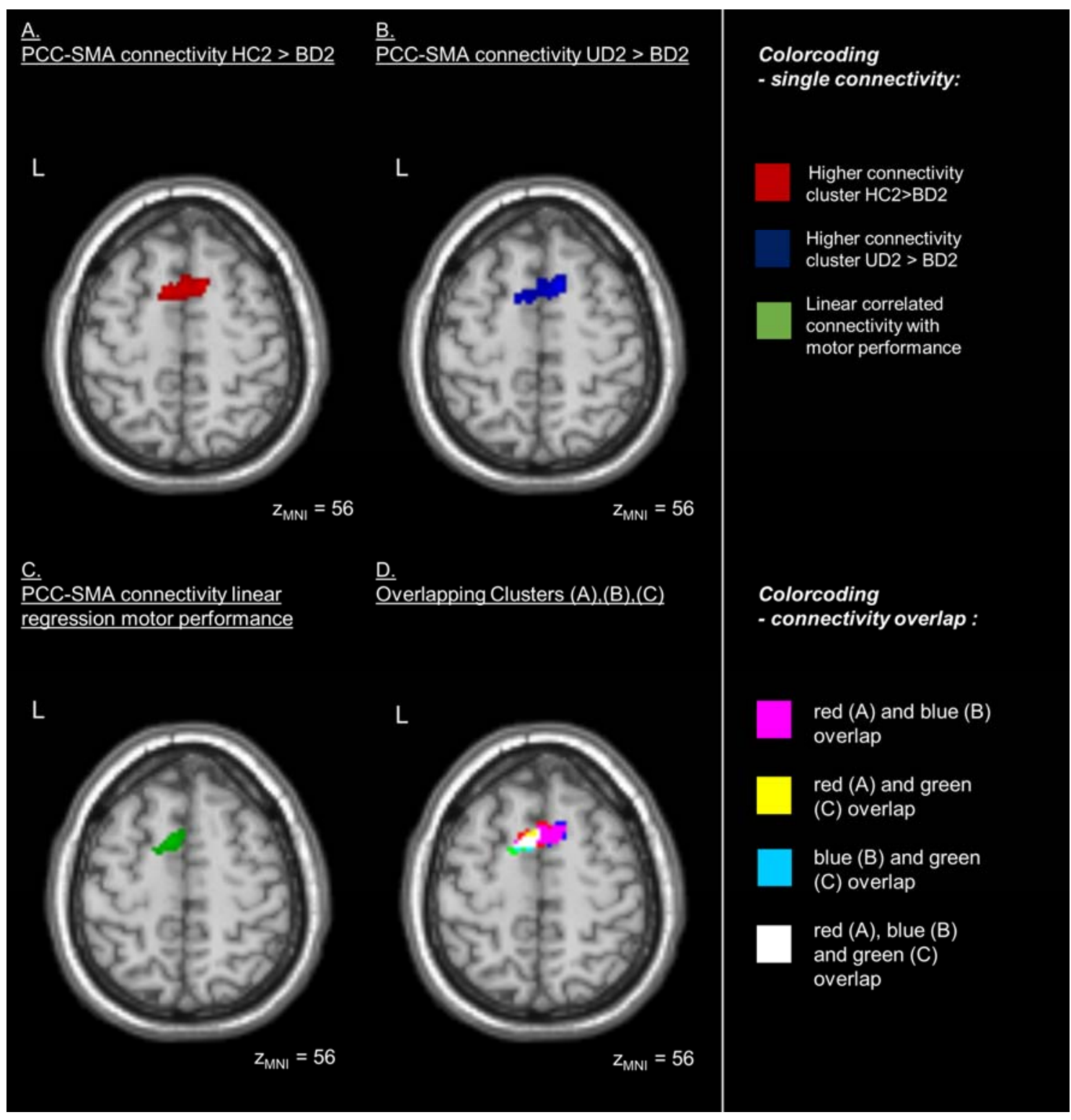

436 Figure 5 PCC connectivity overlaps in the SMA Resting state functional connectivity differences of the 437 posterior cingulate cortex (PCC) between groups and connectivity of the PCC correlated with motor 438 performance overlap in the supplementary motor area (SMA) at an axial plane ( $\left.\mathrm{z}_{\mathrm{MNI}}=56, p F W E c<0.05\right)$. (A) 439 Healthy control subjects (HC2) show higher connectivity than the bipolar depressive subjects (BD2) at visit 2. 440 (B) Unipolar depressive subjects (UD2) present higher connectivity than the bipolar depressive subjects (BD2) 
medRxiv preprint doi: https://doi.org/10.1101/2021.11.26.21266905; this version posted November 28, 2021. The copyright holder for this preprint (which was not certified by peer review) is the author/funder, who has granted medRxiv a license to display the preprint in perpetuity.

All rights reserved. No reuse allowed without permission.

Right
hemisphere
hand M1
connectivity
BD $>$ UD

Right
hemisphere
hand M1
connectivity
BD $>$ UD

Right
hemisphere
hand M1
connectivity
BD $>$ UD

Right
hemisphere
hand M1
connectivity
BD $>$ UD

Right
hemisphere
hand M1
connectivity
BD $>$ UD at visit 2. (C) The connectivity of the PCC to a part of the left SMA is correlated with the motor performance in the finger-tapping-task. (D) The SMA connectivity clusters seen in (A, red), (B, blue) and (C, green) overlap in different extensions, as represented in pink $(A \cap B)$, yellow $(A \cap C)$, turquoise $(B \cap C)$ and white $(A \cap B \cap C)$.

\subsubsection{M1 seed based functional connectivity}

The positive functional connectivity between the right hemisphere hand M1 and the SMA could be shown at $p F W E<0.05$ for each of the groups. Additionally, other parts of the SMN, namely the pre- and postcentral gyrus bilaterally as well as bilateral temporal regions were identified. No negative correlation was evidenced at $p F W E<0.05$ (data not shown).

A higher connectivity between the M1 and the SMA was seen in HC compared to UD only at visit $2(p F W E c<0.05)$ in the model where the medication load was inserted as regressor-ofno-interest. When excluding the lefthanders from the model with medication load as a regressor-of-no-interest, a higher connectivity between the right hemisphere hand M1 and the SMA was also seen at visit 1 at $p F W E c<0.05$ threshold.

Compared to UD, BD showed stronger connectivity between M1 and SMA on both visits (Fig. 6). At the first visit, these clusters survived $p F W E<0.05$ correction. At the second visit, differences were more restricted and seen only in the left hemisphere at $p F W E c<0.05$ level. These differences between BD and UD held in the model with medication load as a regressor-of-no-interest as well as in the model without lefthanders. There was no connectivity of the M1 that was stronger in UD than in BD.

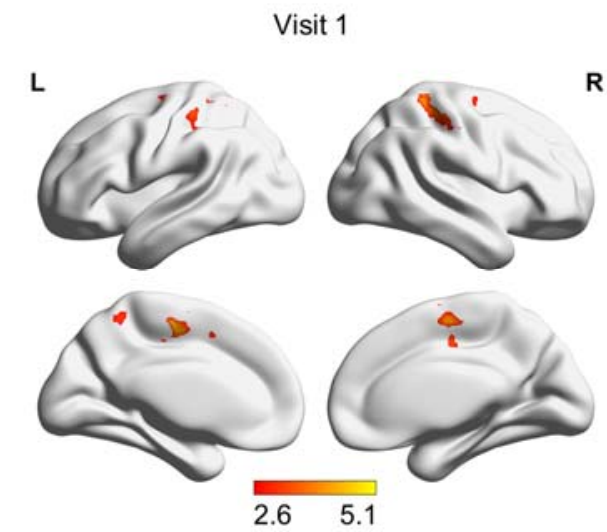

R L
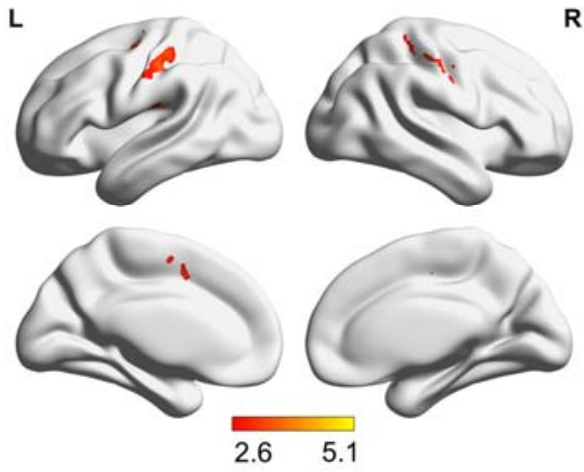

461 Figure 6 M1 connectivity difference Differences in the resting state functional connectivity of the right 462 hemisphere hand motor area (M1) between bipolar (BD) and unipolar (UD) depressed participants at $p$ $463 F W E c<0.05$. BD showed stronger connectivity than UD between M1 and the bilateral SMA in visit 1 than in 464 visit 2. No regions were evidenced in the UD>BD contrast. Colorbar represents t-values. 
465 The linear regression of motor performance score and the right hemisphere hand M1-SMA

466 functional connectivity did not show SMA clusters that survived $p F W E c<0.05$ correction,

467 i.e. there was no correlation between the motor performance and functional connectivity

468 between SMA and M1. This result remained when excluding the lefthanders from the model.

469 All groups did not show changes of their right hemisphere hand M1 connectivity across time.

470 Beyond our a priori hypotheses, higher connectivity in HC than UD at visit 2 between the 471 right hemisphere hand M1 and the right Rolandic operculum was seen (p FWE < 0.05). When 472 controlling for the medication load as a regressor-of-no-interest, the cluster at the right 473 Rolandic operculum was not seen. Furthermore, the cluster was not present, when excluding 474 the lefthanders from the analysis. There was no further difference between BD and HC in any 475 of these models.

476 Finally, to check for potential bias in the seed model, we evaluated whether differences in 477 movement exists during the scanning sessions, in spite of applying a strict motion correction 478 procedure in the analysis. When comparing the frame-by-frame displacement with root479 mean-squares ${ }^{58}$ between the three groups, a difference was revealed, which do not seem to 480 stem from a difference between the HC-BD groups (post-hoc $p=0.257$ ), but rather from a 481 trend between the UD-BD groups (post-hoc $p=0.062$ ) (for detailed results see 482 Supplementary material, chapter 2.3).

\section{3.4 SMN-DMN correlation coefficients}

484 The correlation coefficients between SMN and DMN were computed and compared between 485 groups and across time in rmANOVAs (for results see Supplementary material, chapter 2.4, 486 Table 6). In the linear regressions, the motor performance scores neither showed a 487 relationship with the correlation of SMN and posterior DMN (visit 1: $r<0.001, p=0.903$; 488 visit 2: $r=0.001, p=0.772$ ), nor with the correlation of SMN and anterior DMN on any of 489 the visits (visit 1: $r=0.005, p=0.375$; visit 2: $r=0.002, p=0.700$ ). Similar to the models 490 with lefthanders, no linear relationship between SMN-DMN correlation and motor 491 performance was seen for visit 1 or visit 2. 
medRxiv preprint doi: https://doi.org/10.1101/2021.11.26.21266905; this version posted November 28, 2021. The copyright holder for this

\section{4. Discussion}

493 The current study examined the neural underpinnings of motor performance between groups

494 of BD, UD and HC participants with comparable sex, age, education, medication load and 495 history of disease. We identified a deficit in the FFT motor performance only in BD in 496 relation to $\mathrm{HC}$, which decreased after five weeks of psychopharmacotherapy. As expected, an 497 association between the FTT motor performance and the negative functional connectivity 498 between PCC and SMA was evidenced, which in the explorative investigation did not extend 499 to the relationship between DMN-SMN correlations. Contrary to our expectations, an 500 association between FTT motor performance and positive functional connectivity between

501 M1 and SMA was not observed, suggesting that the contribution of M1 is less relevant than 502 that of PCC in this case.

503 Although the motor circuit is one of the best described in the literature, ${ }^{\text {for review see } 67}$ functional 504 brain alterations in motor areas as part of depressive episodes remain poorly explored. In line 505 with a former study showing the importance of the PCC-SMA connectivity for upper limb 506 motor tasks, ${ }^{17}$ we were able to show here that this connectivity also appears critical for the 507 FTT performance. Since connectivity between PCC-SMA is linearly correlated with the FTT 508 performance, which is impaired in $\mathrm{BD}$ compared to $\mathrm{HC}$, one can assume that the functional 509 brain difference between groups would explain the behavioral difference in the FTT. Despite 510 these promising findings, one must consider that such results do not survive multiple testing 511 correction $(F W E c<0.05)$, when excluding the lefthanders, although they remain identifiable 512 at the threshold $p<0.001$. Rather than the lack of such connectivity effects in the model

513 without lefthanders, the existence of these findings at this threshold supports the notion of a 514 drop in power in detecting statistical differences. To our knowledge, this is the first time that 515 PCC-SMA connectivity has been evaluated and identified as critical for motor performance 516 in a study involving depressive and healthy subjects.

517 Psychomotor alterations are commonly seen in BD and sometimes in UD compared to HC, 518 which has been suggested as a factor that negatively contributes to treatment response or even 519 remission. ${ }^{24,25}$ Therefore, this remains a very relevant topic of research. In line with a former 520 study comparing psychomotor performance in $\mathrm{UD}, \mathrm{BD}$ and $\mathrm{HC},{ }^{33}$ we report evidence that $\mathrm{BD}$ 521 are more likely to have an impairment in motor performance measured by the FTT. This 522 finding is also in line with the literature showing more robust FTT impairment in $\mathrm{BD}^{18,19}$ than 
medRxiv preprint doi: https://doi.org/10.1101/2021.11.26.21266905; this version posted November 28, 2021. The copyright holder for this

523 in UD, where it appears compromised only in some study samples. ${ }^{5,20,21,37-39}$ Overall,

524 learning effects seem to be present from the first FTT assessment to the second, differently

525 from previously shown. ${ }^{68}$ In a keyboard naive population from Kenya, it was seen that such

526 learning effects only appeared in healthy controls and not in depressive subjects. ${ }^{39}$ A possible

527 explanation for the improvement in the FTT performance could be that depressive patients in

528 our study were able to profit from treatment, which may have reflected at least partially in

529 their performance. This is an interesting hypothesis involving possible neuroplasticity

530 changes that could be addressed in the future.

531 The hypothesis that the resting state functional connectivity between the M1 and the SMA is

532 not only critical for the motor performance in $\mathrm{HC},{ }^{42}$ but also in UD and BD, was rejected

533 since the linear regressions with motor performance did not show correlated clusters in the

534 SMA when seeding the right hemisphere hand M1. As far as we know, this work is the first

535 providing evidence that right hemisphere hand M1-SMA connectivity is not critical for

536 influencing FTT motor performance in depressive subjects. Another possibility for negative

537 findings is that the seed method in Herszage et $a .^{42}$ when detecting the functional

538 representation of the hand with transcranial magnetic stimulation for each subject, could have

539 been more precise. Since our method of seed determination includes not only functional but

540 also individual anatomical information, it would be interesting to compare the two seeding

541 methods in future studies to define the most promising way of detecting individual seeds.

542 Our results show that BD have a higher M1-SMA connectivity than UD at both timepoints.

543 Since we did not find behavioral differences in the FTT between the two patient groups, we

544 can only hypothesize that the M1-SMA connectivity might have relevance for other

545 symptoms of depression that were beyond the scope of this work. Groups, both BD and UD

546 were comparably depressed, in a moderate level according to BDI-II scores, but only the UD

547 improved significantly in the second evaluation, which might be a limitation when comparing

548 the longitudinal changes during treatment. We speculate that residual psychomotor symptoms

549 in BD, including the differences seen in neural correlates, may contribute for the limited

550 improvement since psychomotor retardation is known as a negative predictor for

551 antidepressant treatment response. ${ }^{69}$ All individual seeds used for M1 and PCC functional

552 connectivity analysis have been carefully created and inspected for structural accuracy of

553 each individual anatomy aiming at the participant's hand knob. Furthermore, their volumes

554 did not differ across groups, which per se could lead to false conclusions. Finally, we 
medRxiv preprint doi: https://doi.org/10.1101/2021.11.26.21266905; this version posted November 28, 2021. The copyright holder for this

555 carefully controlled our main findings for medication load and movement during scanning 556 sessions, where we found no evidence that our main findings might have been biased from 557 these covariates. A trend difference of movement between groups should be kept in mind. To 558 best remove potential bias stemming from movement, we used movement correction with 559 ICA-AROMA which was shown to be very efficient ${ }^{70}$ and extended it with manual checking 560 for artificial signals, so we believe that our results from BD-UD comparison are not biased by 561 movement. In our view, our results also open new research perspectives for the comparisons 562 between patient groups. For example, it may be interesting in the future to use motor 563 paradigms that comprise a motor planning component, which may be more sensitive in 564 detecting differences in behavior between UD and BD. This approach can be useful in new 565 ways to support early differential diagnosis where there is a clear clinical need. ${ }^{71}$

566 It was postulated that the imbalance between the SMN and the DMN is critical for motor 567 performance in depression. ${ }^{\text {for }}$ review see 6 Therefore, it might be expected that the 568 interconnection between the SMN and DMN, as a task positive and a task negative network 569 respectively ${ }^{47,72}$, is critical for motor performance in the FTT. To explore whether this model 570 could explain the motor performance differences in a more consistent way than our seed 571 model would, we computed individual correlation coefficients between SMN and DMN. The 572 idea that the SMN-DMN connectivity is critical for FTT was rejected, since no linear 573 relationship between correlation coefficients and the motor performance were revealed. It is 574 possible that a model taking into account the imbalance between whole networks containing 575 many regions is likely to oversimplify more complex neural mechanisms in this case.

576 Some potential limitations need to be mentioned, which make our results be viewed with 577 caution. Our sample size is comparable to other studies, but likely modest taking into account 578 the limited power in detecting differences when excluding the lefthanders. Therefore, a 579 replication of our findings with larger samples is prudent. Another important aspect is the use 580 of medication, which has been very tightly controlled, but still could have influenced the 581 results in unpredictable ways. Probably due to fast switches in mood, not all BD were rated 582 with depressive symptoms at a clinical threshold at the day of testing and some also showed a 583 combination of depressive and manic symptoms (mixed episode), which might be a limitation 584 of this study but reflects clinical reality. Noteworthy, considering that BD can be often 585 misdiagnosed as UD, ${ }^{71}$ we observed the occurrence of manic symptoms in one patient part of 586 the UD group, for whom the YMRS was in the clinical range. Nevertheless, all patients 
medRxiv preprint doi: https://doi.org/10.1101/2021.11.26.21266905; this version posted November 28, 2021. The copyright holder for this preprint (which was not certified by peer review) is the author/funder, who has granted medRxiv a license to display the preprint in perpetuity.

All rights reserved. No reuse allowed without permission.

587 included in this study had a long history of disease and a diagnosis confirmed by multiple 588 caregivers of the clinical setting, which reduces the risk of a BD being misdiagnosed as 589 UD. $^{71,73}$

590 In conclusion, our seed model supports the notion that functional connectivity between PCC-

591 SMA explains the FTT performance in healthy and depressed individuals, but the functional 592 connectivity between M1-SMA does not. Reinforcing the relevance and originality of these 593 findings, the SMN-DMN correlation did not explain motor performance as the seed model.

\section{5. Funding}

595 This work was supported by the University Medical Center Göttingen (UMG) and the 596 German Federal Ministry of Education and Research (Bundesministerium fuer Bildung und 597 Forschung, BMBF: 01 ZX 1507, “PreNeSt - e:Med”).

\section{6. Competing interests}

599 The authors report no competing interests.

600 7. Acknowledgements

601 We would like to thank PD Dr. Peter Dechent and Dr. Carsten Schmidt-Samoa for their 602 support and advice.

\section{8. References}

604 1. Gardini S, Venneri A, McGeown WJ, et al. Brain Activation Patterns Characterizing 605 Different Phases of Motor Action: Execution, Choice and Ideation. Brain Topogr. 606 2016;29(5):679-692. doi:10.1007/s10548-016-0491-5

607 2. Grafton ST, Hamilton AF de C. Evidence for a distributed hierarchy of action 608 representation in the brain. Hum Mov Sci. 2007;26(4):590-616. 609 doi:10.1016/j.humov.2007.05.009

610 3. Witt ST, Laird AR, Meyerand ME. Functional neuroimaging correlates of finger611 tapping task variations: An ALE meta-analysis. NeuroImage. 2008;42(1):343-356. 612 doi:10.1016/j.neuroimage.2008.04.025 
medRxiv preprint doi: https://doi.org/10.1101/2021.11.26.21266905; this version posted November 28, 2021. The copyright holder for this preprint (which was not certified by peer review) is the author/funder, who has granted medRxiv a license to display the preprint in perpetuity. All rights reserved. No reuse allowed without permission.

613 4. Liberg B, Adler M, Jonsson T, et al. The neural correlates of self-paced finger tapping 614 in bipolar depression with motor retardation. Acta Neuropsychiatr. 2013;25(1):43-51. 615 doi:10.1111/j.1601-5215.2012.00659.x

616 5. Genzel L, Dresler M, Cornu M, et al. Medial Prefrontal-Hippocampal Connectivity and 617 Motor Memory Consolidation in Depression and Schizophrenia. Biol Psychiatry. 2015;77(2):177-186. doi:10.1016/j.biopsych.2014.06.004

7. Sarkheil P, Odysseos P, Bee I, Zvyagintsev M, Neuner I, Mathiak K. Functional connectivity of supplementary motor area during finger-tapping in major depression. Compr Psychiatry. 2020;99:152166. doi:10.1016/j.comppsych.2020.152166

8. Roland PE, Larsen B, Lassen NA, Skinhoj E. Supplementary motor area and other cortical areas in organization of voluntary movements in man. $J$ Neurophysiol. 1980;43(1):118-136. doi:10.1152/jn.1980.43.1.118

9. Boschert J, Hink RF, Deecke L. Finger movement versus toe movement-related potentials: Further evidence for supplementary motor area (SMA) participation prior to voluntary action. Exp Brain Res. 1983;52(1):73-80. doi:10.1007/BF00237151

10. Jo H-G, Habel U, Schmidt S. Role of the supplementary motor area in auditory sensory attenuation. Brain Struct Funct. 2019;224(7):2577-2586. doi:10.1007/s00429-01901920-x

11. Nachev P, Kennard C, Husain M. Functional role of the supplementary and presupplementary motor areas. Nat Rev Neurosci. 2008;9(11):856-869. doi:10.1038/nrn2478

12. Rolls ET. The cingulate cortex and limbic systems for emotion, action, and memory.

13. Berman MG, Peltier S, Nee DE, Kross E, Deldin PJ, Jonides J. Depression, rumination and the default network. Soc Cogn Affect Neurosci. 2011;6(5):548-555. doi:10.1093/scan/nsq080

14. Ho TC, Connolly CG, Henje Blom E, et al. Emotion-Dependent Functional Connectivity of the Default Mode Network in Adolescent Depression. Biol Psychiatry. 2015;78(9):635-646. doi:10.1016/j.biopsych.2014.09.002

15. Preuss A, Bolliger B, Schicho W, et al. SSRI Treatment Response Prediction in Depression Based on Brain Activation by Emotional Stimuli. Front Psychiatry. 2020;11:1071. doi:10.3389/fpsyt.2020.538393

16. Zhou H-X, Chen X, Shen Y-Q, et al. Rumination and the default mode network: Metaanalysis of brain imaging studies and implications for depression. NeuroImage. 2020;206:116287. doi:10.1016/j.neuroimage.2019.116287 
medRxiv preprint doi: https://doi.org/10.1101/2021.11.26.21266905; this version posted November 28, 2021. The copyright holder for this preprint (which was not certified by peer review) is the author/funder, who has granted medRxiv a license to display the preprint in perpetuity. All rights reserved. No reuse allowed without permission.

652 17. Wu CW, Lin S-HN, Hsu L-M, et al. Synchrony Between Default-Mode and

653

654

655

656

657

658

659

660

661

662

663

664

665

666

667

668

669

670

671

672

673

674

675

676

677

678

679

680

681

682

683

684

685

686

687

688

689

690

Sensorimotor Networks Facilitates Motor Function in Stroke Rehabilitation: A Pilot fMRI Study. Front Neurosci. 2020;14. doi:10.3389/fnins.2020.00548

18. Coffman JA, Bornstein RA, Olson SC, Schwarzkopf SB, Nasrallah HA. Cognitive impairment and cerebral structure by MRI in bipolar disorder. Biol Psychiatry. 1990;27(11):1188-1196. doi:10.1016/0006-3223(90)90416-Y

19. Shinn AK, Yuksel C, Masters G, et al. Procedural memory consolidation after a night of sleep in bipolar disorder with psychotic features. Schizophr Res. 2019;210:299-300. doi:10.1016/j.schres.2018.12.044

20. Hueng T-T, Lee IH, Guog Y-J, et al. Is a patient-administered depression rating scale valid for detecting cognitive deficits in patients with major depressive disorder? Psychiatry Clin Neurosci. 2011;65(1):70-76. doi:10.1111/j.1440-1819.2010.02166.x

21. Lee CJ, Lee L-T, Tsai HC, et al. Factors related to metabolic parameters in medicated patients with major depressive disorder-a naturalistic study. Psychiatry Res. 2018;268:28-33. doi:10.1016/j.psychres.2018.06.061

22. World Health Organization, ed. The ICD-10 Classification of Mental and Behavioural Disorders: Diagnostic Criteria for Research. World Health Organization; 1993.

23. American Psychiatric Association, American Psychiatric Association, eds. Diagnostic and Statistical Manual of Mental Disorders: DSM-5. 5th ed. American Psychiatric Association; 2013.

24. Ulbricht CM, Dumenci L, Rothschild AJ, Lapane KL. Changes in Depression Subtypes Among Men in STAR*D: A Latent Transition Analysis. Am J Mens Health. 2018;12(1):5-13. doi:10.1177/1557988315607297

25. Janzing JGE, Birkenhäger TK, van den Broek WW, Breteler LMT, Nolen WA, Verkes R-J. Psychomotor Retardation and the prognosis of antidepressant treatment in patients with unipolar Psychotic Depression. J Psychiatr Res. 2020;130:321-326. doi:10.1016/j.jpsychires.2020.07.020

26. Young KS, Parsons CE, Stein A, Kringelbach ML. Motion and emotion: depression reduces psychomotor performance and alters affective movements in caregiving interactions. Front Behav Neurosci. 2015;9:26. doi:10.3389/fnbeh.2015.00026

27. Almeida JRC, Phillips ML. Distinguishing between Unipolar Depression and Bipolar Depression: Current and Future Clinical and Neuroimaging Perspectives. Biol Psychiatry. 2013;73(2):111-118. doi:10.1016/j.biopsych.2012.06.010

28. Downar J, Daskalakis ZJ. New Targets for rTMS in Depression: A Review of Convergent Evidence. Brain Stimulat. 2013;6(3):231-240. doi:10.1016/j.brs.2012.08.006

29. Swann AC, Katz MM, Bowden CL, Berman NG, Stokes PE. Psychomotor performance and monoamine function in bipolar and unipolar affective disorders. Biol Psychiatry. 1999;45(8):979-988. doi:10.1016/S0006-3223(98)00172-3 
691

692

693

694

695

696

697

698

699

700

701

702

703

704

705

706

707

708

709

710

711

712

713

714

715

716

717

718

719

720

721

722

723

724

725

726

727

728

729

30. Werf-Eldering MJ van der, Burger H, Holthausen EAE, Aleman A, Nolen WA. Cognitive Functioning in Patients with Bipolar Disorder: Association with Depressive Symptoms and Alcohol Use. PLOS ONE. 2010;5(9):e13032. doi:10.1371/journal.pone.0013032

31. Sasayama D, Hori H, Teraishi T, et al. More severe impairment of manual dexterity in bipolar disorder compared to unipolar major depression. $J$ Affect Disord. 2012;136(3):1047-1052. doi:10.1016/j.jad.2011.11.031

32. Snyder HR. Major Depressive Disorder is Associated with Broad Impairments on Neuropsychological Measures of Executive Function: A Meta-Analysis and Review. Psychol Bull. 2013;139(1):81-132. doi:10.1037/a0028727

33. Blackburn IM. Mental and Psychomotor Speed in Depression and Mania. $\mathrm{Br} J$ Psychiatry. 1975;126(4):329-335. doi:10.1192/bjp.126.4.329

34. Popescu C, Ionescu R, Jipescu I, Popa S. Psychomotor functioning in unipolar and bipolar affective disorders. Romanian J Neurol Psychiatry Rev Roum Neurol Psychiatr. 1991;29(1-2):17-33.

35. Walker MP, Brakefield T, Morgan A, Hobson JA, Stickgold R. Practice with Sleep Makes Perfect: Sleep-Dependent Motor Skill Learning. Neuron. 2002;35(1):205-211. doi:10.1016/S0896-6273(02)00746-8

36. Walker MP, Brakefield T, Seidman J, Morgan A, Hobson JA, Stickgold R. Sleep and the Time Course of Motor Skill Learning. Learn Mem. 2003;10(4):275-284. doi:10.1101/lm.58503

37. Dresler M, Kluge M, Genzel L, Schüssler P, Steiger A. Impaired off-line memory consolidation in depression. Eur Neuropsychopharmacol. 2010;20(8):553-561. doi:10.1016/j.euroneuro.2010.02.002

38. Dresler M, Kluge M, Pawlowski M, Schüssler P, Steiger A, Genzel L. A double dissociation of memory impairments in major depression. $J$ Psychiatr Res. 2011;45(12):1593-1599. doi:10.1016/j.jpsychires.2011.07.015

39. Genzel L, Ali E, Dresler M, Steiger A, Tesfaye M. Sleep-dependent memory consolidation of a new task is inhibited in psychiatric patients. $J$ Psychiatr Res. 2011;45(4):555-560. doi:10.1016/j.jpsychires.2010.08.015

40. Rock PL, Roiser JP, Riedel WJ, Blackwell AD. Cognitive impairment in depression: a systematic review and meta-analysis. Psychol Med. 2014;44(10):2029-2040. doi:10.1017/S0033291713002535

41. Roca M, Monzón S, Vives $\mathrm{M}$, et al. Cognitive function after clinical remission in patients with melancholic and non-melancholic depression: A 6 month follow-up study. J Affect Disord. 2015;171:85-92. doi:10.1016/j.jad.2014.09.018

42. Herszage J, Dayan E, Sharon H, Censor N. Explaining Individual Differences in Motor Behavior by Intrinsic Functional Connectivity and Corticospinal Excitability. Front Neurosci. 2020;14. doi:10.3389/fnins.2020.00076 
medRxiv preprint doi: https://doi.org/10.1101/2021.11.26.21266905; this version posted November 28, 2021. The copyright holder for this preprint (which was not certified by peer review) is the author/funder, who has granted medRxiv a license to display the preprint in perpetuity. All rights reserved. No reuse allowed without permission.

43. Martino M, Magioncalda $\mathrm{P}$, Huang $\mathrm{Z}$, et al. Contrasting variability patterns in the default mode and sensorimotor networks balance in bipolar depression and mania. Proc Natl Acad Sci. 2016;113(17):4824-4829. doi:10.1073/pnas.1517558113

44. Liu M, Wang Y, Zhang A, et al. Altered dynamic functional connectivity across mood states in bipolar disorder. Brain Res. 2021;1750:147143. doi:10.1016/j.brainres.2020.147143

45. Goya $\square$ Maldonado R, Brodmann K, Keil M, Trost S, Dechent P, Gruber O. Differentiating unipolar and bipolar depression by alterations in large-scale brain networks. Hum Brain Mapp. 2016;37(2):808-818. doi:10.1002/hbm.23070

46. Russo D, Martino M, Magioncalda P, Inglese M, Amore M, Northoff G. Opposing Changes in the Functional Architecture of Large-Scale Networks in Bipolar Mania and Depression. Schizophr Bull. 2020;46(4):971-980. doi:10.1093/schbul/sbaa004

47. Kelly AMC, Uddin LQ, Biswal BB, Castellanos FX, Milham MP. Competition between functional brain networks mediates behavioral variability. NeuroImage. 2008;39(1):527537. doi:10.1016/j.neuroimage.2007.08.008

48. Oldfield RC. The assessment and analysis of handedness: the Edinburgh inventory. Neuropsychologia. 1971;9(1):97-113. doi:10.1016/0028-3932(71)90067-4

49. Uher R, Farmer A, Maier W, et al. Measuring depression: comparison and integration of three scales in the GENDEP study. Psychol Med. 2008;38(2):289-300. doi: $10.1017 /$ S0033291707001730

50. Milak MS, Keilp J, Parsey RV, Oquendo MA, Malone KM, Mann JJ. Regional brain metabolic correlates of self-reported depression severity contrasted with clinician ratings. J Affect Disord. 2010;126(1):113-124. doi:10.1016/j.jad.2010.03.002

51. Phillips ML, Travis MJ, Fagiolini A, Kupfer DJ. Medication Effects in Neuroimaging Studies of Bipolar Disorder. Am J Psychiatry. 2008;165(3):313-320. doi:10.1176/appi.ajp.2007.07071066

52. Hassel S, Almeida JR, Kerr N, et al. Elevated striatal and decreased dorsolateral prefrontal cortical activity in response to emotional stimuli in euthymic bipolar disorder: no associations with psychotropic medication load. Bipolar Disord. 2008;10(8):916927. doi:10.1111/j.1399-5618.2008.00641.x

53. Versace A, Almeida JRC, Hassel S, et al. Elevated Left and Reduced Right Orbitomedial Prefrontal Fractional Anisotropy in Adults With Bipolar Disorder Revealed by Tract-Based Spatial Statistics. Arch Gen Psychiatry. 2008;65(9):10411052. doi:10.1001/archpsyc.65.9.1041

54. Almeida JRC, Akkal D, Hassel S, et al. Reduced gray matter volume in ventral prefrontal cortex but not amygdala in bipolar disorder: significant effects of gender and $\begin{array}{llll}\text { trait } \quad \text { anxiety. } & \text { Psychiatry 2009;171(1):54-68. }\end{array}$ doi:10.1016/j.pscychresns.2008.02.001 
medRxiv preprint doi: https://doi.org/10.1101/2021.11.26.21266905; this version posted November 28, 2021. The copyright holder for this preprint (which was not certified by peer review) is the author/funder, who has granted medRxiv a license to display the preprint in perpetuity. All rights reserved. No reuse allowed without permission.

55. Hassel S, Almeida JR, Frank E, et al. Prefrontal cortical and striatal activity to happy and fear faces in bipolar disorder is associated with comorbid substance abuse and eating disorder. J Affect Disord. 2009;118(1-3):19-27. doi:10.1016/j.jad.2009.01.021

56. Manoach DS, Thakkar KN, Stroynowski E, et al. Reduced overnight consolidation of procedural learning in chronic medicated schizophrenia is related to specific sleep stages. J Psychiatr Res. 2010;44(2):112. doi:10.1016/j.jpsychires.2009.06.011

57. Pruim RHR, Mennes M, van Rooij D, Llera A, Buitelaar JK, Beckmann CF. ICAAROMA: A robust ICA-based strategy for removing motion artifacts from fMRI data. NeuroImage. 2015;112:267-277. doi:10.1016/j.neuroimage.2015.02.064

58. Van Dijk KRA, Sabuncu MR, Buckner RL. The influence of head motion on intrinsic functional connectivity MRI. NeuroImage. 2012;59(1):431-438. doi:10.1016/j.neuroimage.2011.07.044

59. Hardwick RM, Rottschy C, Miall RC, Eickhoff SB. A quantitative meta-analysis and review of motor learning in the human brain. Neuroimage. 2013;67:283-297. doi:10.1016/j.neuroimage.2012.11.020

60. Beckmann CF, Smith SM. Probabilistic independent component analysis for functional magnetic resonance imaging. IEEE Trans Med Imaging. 2004;23(2):137-152. doi:10.1109/TMI.2003.822821

61. Shaw ED, Stokes PE, Mann JJ, Manevitz AZ. Effects of lithium carbonate on the memory and motor speed of bipolar outpatients. J Abnorm Psychol. 1987;96(1):64-69. doi:10.1037/0021-843X.96.1.64

62. Shimoyama I, Ninchoji T, Uemura K. The Finger-Tapping Test: A Quantitative Analysis. Arch Neurol. 1990;47(6):681-684. doi:10.1001/archneur.1990.00530060095025

63. Calugi S, Cassano GB, Litta A, et al. Does psychomotor retardation define a clinically relevant phenotype of unipolar depression? J Affect Disord. 2011;129(1-3):296-300. doi:10.1016/j.jad.2010.08.004

64. Jiménez-Jiménez FJ, Calleja M, Alonso-Navarro H, et al. Influence of age and gender in motor performance in healthy subjects. $J$ Neurol Sci. 2011;302(1):72-80. doi:10.1016/j.jns.2010.11.021

65. Prigatano GP, Goncalves CWP, Oliveira SB de, Denucci SM, Pereira RM, Braga LW. Kinematic recordings while performing a modified version of the Halstead Finger Tapping Test: Age, sex, and education effects. J Clin Exp Neuropsychol. 2020;42(1):4254. doi:10.1080/13803395.2019.1665170

66. Tzourio-Mazoyer N, Landeau B, Papathanassiou D, et al. Automated Anatomical Labeling of Activations in SPM Using a Macroscopic Anatomical Parcellation of the MNI MRI Single-Subject Brain. NeuroImage. 2002;15(1):273-289. doi:10.1006/nimg.2001.0978

67. Arber S. Motor Circuits in Action: Specification, Connectivity, and Function. Neuron. 2012;74(6):975-989. doi:10.1016/j.neuron.2012.05.011 
medRxiv preprint doi: https://doi.org/10.1101/2021.11.26.21266905; this version posted November 28, 2021. The copyright holder for this

preprint (which was not certified by peer review) is the author/funder, who has granted medRxiv a license to display the preprint in perpetuity.

All rights reserved. No reuse allowed without permission.

808 68. Fischer S, Hallschmid M, Elsner AL, Born J. Sleep forms memory for finger skills. Proc Natl Acad Sci. 2002;99(18):11987-11991. doi:10.1073/pnas.182178199

69. Caligiuri MP, Gentili V, Eberson S, Kelsoe J, Rapaport M, Gillin JC. A quantitative neuromotor predictor of antidepressant non-response in patients with major depression. J Affect Disord. 2003;77(2):135-141. doi:10.1016/S0165-0327(02)00107-6

70. Pruim RHR, Mennes M, Buitelaar JK, Beckmann CF. Evaluation of ICA-AROMA and alternative strategies for motion artifact removal in resting state fMRI. NeuroImage. 2015;112:278-287. doi:10.1016/j.neuroimage.2015.02.063

71. Hirschfeld RMA, Vornik LA, Lewis L. Perceptions and Impact of Bipolar Disorder: How Far Have We Really Come? Results of the National Depressive and ManicDepressive Association 2000 Survey of Individuals With Bipolar Disorder. J Clin Psychiatry. 2003;64(2):161-174.

72. Fox MD, Snyder AZ, Vincent JL, Corbetta M, Van Essen DC, Raichle ME. The human brain is intrinsically organized into dynamic, anticorrelated functional networks. Proc Natl Acad Sci U S A. 2005;102(27):9673-9678. doi:10.1073/pnas.0504136102

73. Ghaemi SN, Sachs GS, M. Chiou A, Pandurangi AK, Goodwin FK. Is bipolar disorder still underdiagnosed? Are antidepressants overutilized? J Affect Disord. 1999;52(1):135144. doi:10.1016/S0165-0327(98)00076-7 